\title{
A tecnologia de realidade virtual como recurso para formação em saúde pública à distância: uma aplicação para a aprendizagem dos procedimentos antropométricos
}

\author{
The technology of virtual reality resource for formation \\ in public health in the distance: an application \\ for the learning of anthropometric procedures
}

Elomar Christina Vieira Castilho Barilli ${ }^{1}$

Nelson Francisco Favilla Ebecken ${ }^{2}$

Gerson Gomes Cunha ${ }^{2}$

\footnotetext{
${ }^{1}$ Fundação Oswaldo Cruz. Rua Leopoldo Bulhões 1.480/Pavilhão Joaquim Cardoso de M ello/301, $M$ anguinhos. 21041-210 Rio deJaneiro RJ. barilli@ead.fiocruz.br 2Universidade Federal do Rio deJaneiro.
}

Abstract This article presents the research developed in the Laboratory of Computational M ethods in Engineering of the Federal University of Rio de Janeiro in partnership with the Program of Distance Education of the $\mathrm{N}$ ational School of Public H ealth Sergio Arouca (ENSP), approaching the integration between Distance Education and Virtual Reality (VR) technology as reply to the public health educative demands that require the development of motor abilities. The application field wastheformation of the professionals of the Food and Nutritional Surveillance, as is the base of one of the Brazilian public policies targeting the monitoring of lacks of nutrients. The prototype consists of a complementary virtual environment, supported in VR for the M onitoring of Food and Nutritional specialization course, that is part of the regulate courses of the Distance Education of ENSP approaching the anthropometric procedures for being the most used in the survey of the nutritional state of the population. A total of 189 participants visited the Virtual Environment and it could be evidenced that the VR can be used as a pedagogical resource to collaborate with the processes of professional distance education, that demand the development of motor abilities.

Key words Virtual reality, Distance education, Anthropometry, Public health
Resumo 0 presente artigo apresenta a pesquisa desenvolvida no Laboratório de M étodos Computacionais em Engenharia da Universidade Federal do Rio de Janeiro em parceria com a Escola Nacional de SaúdePública Sérgio Arouca (ENSP) da Fundação $\mathrm{O}$ swaldo $\mathrm{Cruz}$, abordando a integração educação à distância e realidade virtual (RV) como resposta às demandas educativas da saúde pública que exigem o desenvolvimento de habilidades motoras. 0 campo de aplicação foi a formação dos profissionais do Sistema de Vigilância Alimentar e Nutricional (VAN), por ser a base deuma das políticas públicas brasileiras com alvo no monitoramento das carências de nutrientes. 0 protótipo constitui-se de um ambiente virtual complementar para o curso de aperfeiçoamento em VAN, que integra a oferta de cursos da educação à distância da EN SP, abordando os procedimentos antropométricos por serem os mais utilizados no levantamento do estado nutricional da população. Os ambientes RV foram construídosem linguagem virtual modeling language, utilizada para executar aplicações na Internet. Tendo 189 participantes visitado o ambiente virtual, pôde se constatar a hipótese de quea RV pode ser utilizada como recurso pedagógico para colaborar com os processos de formação profissional à distância que exijam o desenvolvimento de habilidades motoras.

Palavras-chave Realidade virtual, Educação à distância, Antropometria, Saúde pública 
Introdução

A realidade virtual (RV) envolve tecnologias re volucionárias para o desenvolvimento de aplicações, em função de novas possibilidades que oferece para o interfaceamento (sistema/usuário) com o uso de dispositivos multissensoriais, navegação em espaços tridimensionais, imersão no contexto da aplicação e interação em tempo real, ampliando os sentidos anteriormente ligados à simples visualização, audição e manipulação tridimensional, para 0 tato, pressão e até olfato ${ }^{1}$. Além dessas características, devido ao foco educativo do projeto, a RV foi utilizada no presente estudo devido à sua capacidade de prover um ambiente motivador, amigável, de fácil utilização, desenvolvimento a baixo custo e por ainda ser capaz de inserir o aprendiz em contextos que refletem a sua própria realidade.

Considera-se que a utilização da RV conformará um novo paradigma de aprendizagem das novas gerações, migrando para o conceito de aprender-conhecer-sentir-comunicar, em vez de, simplesmente, aprender-conhecer-comunicar ${ }^{2}$, entendendo o termo "sentir" como utilizar os sentidos.

A fim de que o projeto se desenvolvesse, foi criado um protótipo (ambiente virtual - AV), apoiado em RV, disponibilizado na Internet, enfocando o campo dos serviços de saúde pública da Vigilância Alimentar eN utricional, envolvendo as atividades de coleta de dados referentes à medição e pesagem de pacientes (coleta antropométrica).

Apesar das potencialidades da RV estabelecidas por dispositivos de entrada e saída - luvas, óculos estereoscópicos, capacetes de imersão, além dos dispositivos hápticos (tato) -, este trabalho optou pela utilização da "RV de monitor" (na tela do computador) por considerá-la adequada ao perfil do público-alvo, aliado ao baixo custo de execução.

A elaboração da pesquisa fundamentou-se nos marcos teóricos da educação permanente (socioconstrutivismo, pedagogias libertadora e problematizadora e educação significativa).

0 trabal ho ainda propõe o modelo de avaliação métrico pedagógico (M AM P), o qual prevê a utilização de critérios técnicos e pedagógicos, apoiando-se em pressupostos ligados à interação homem-computador (IHC), goal question metric (GQM) e apreciação analítica ( $A A)$, as quais serão apresentadas mais adiante.

A aplicação do M AM P constitui a metodologia de avaliação do AV, a qual foi dividida em dois momentos, um presencial e outro à distância. Tendo participado 189 voluntários, foi constatada a hipótese de que a tecnologia de RV é adequada para ser utilizada como recurso pedagógico para colaborar com os processos de formação profissional à distância que exijam o desenvolvimento de habilidades físico-motoras.

\section{A tecnologia de RV}

A RV podeser entendida como o "nomegenérico" que representa uma tecnologia em que estão sendo agrupados meios através dos quais o usuário pode livremente visualizar, explorar/manipular e interagir com dados complexos em tempo real ${ }^{3}$. Agrupando-se alguns outros conceitos, pode-se dizer que realidade virtual é uma técnica avançada de interface, capaz de prover, para o usuário, a sensação de imersão (sensação de estar dentro do ambiente), navegação e interação em um ambiente sintético tridimensional gerado por computador, utilizando canais multissen soriais.

A RV pode ser imersiva e não imersiva. A diferença reside na utilização das tecnologias de ordem física - hardware -, apoiadas por outras de ordem lógica - software. Assim, a RV imersiva depende de outros recursos tecnológicos ou dispositivos ditos de "entrada/saída" de informação, como capacetes (head-mounted display HM D), luvas ou até sal as de projeção (caveautomatic virtual environment - CAVE), os quais possibilitam a interação física entre usuário e sistema. Já a RV não imersiva é baseada no uso de monitores contando, portanto, com aparatos físicos mais simples, como monitor e mouse (podem ser incluídos joystiks). A primeira, logicamente, oferece maiores possibilidades de interação e envolvimento. Todavia, dependendo dos objetivos e possibilidades, a RV não imersiva pode ser uma opção factível, uma vez que apresenta aspectos facilitadores tanto para os desenvolvedores de sistemas ( pois não há a necessidade de desenvolver drivers especiais, nem programação muito sofisticada e complexa), bem como para os usuários (podem experimentar os ambientes virtuais com configurações físicas bem mais simples e em qualquer lugar). Tais características, aliadas ao baixo custo de aplicação, podem significar a apropriação desta tecnologia pelo campo da educação em saúde pública.

Podem ser adicionados, ainda, dispositivos sonoros (o som pode ser posicionado oferecendo a sensação de movimento e localização; a experiência auditiva casada com a visual édenomi- 
nada realismo audiovisual), de tato e força, de forma a permitir sensações muito mais realísticas e, ao mesmo tempo, minimizar sua própria presença (dimensão e peso) e, assim, o nível de imersão/interação é potencializado.

Os dispositivos de tato e força são chamados de interfaces hápticas (haptic interfaces) e representam o estudo de como acoplar o sentido do tato humano a um mundo gerado em computador. 0 termo háptico relaciona-se ao tato (do grego haptikós - sensível ao tato), ou seja, significa tátil. M ais recentemente, cunhou-se em inglês o substantivo haptics (em português traduzido como "háptica") para designar a ciência do toque dedicada a estudar e a simular a pressão, a textura, a vibração e outras sensações biológicas relacionadas com o toque. Trata-se de estudos multidisciplinares voltados para entender e desenvolver dispositivos físicos que meçam a interação tátil usuário-sistema4. Os dispositivos hápticos podem ser subdivididos em: (1) de resposta tátil (tactile feedback) - são os dispositivos que provêm a interação com as terminações nervosas da pele que indicam a forma, calor e textura. A sensação de tato provê informações sobre a geometria da superfície, sua textura ou sua temperatura. São muito utilizados em ambientes virtuais onde haja baixa ou nenhuma iluminação (por exemplo, fundo do mar, interior de artérias; (2) de força ou pressão (force feedback ou, ainda, cinestésico) - são dispositivos que interagem com os músculos e os tendões, dando ao ser humano uma sensação de aplicação de uma força em sentido contrário. A sensação de força fornece informações sobre o peso do objeto e sua consistência. Estes dispositivos constituem, principalmente, os manipuladores robóticos que empurram o usuário de encontro às forças que correspondem ao ambientevirtual (estetipo está presente em sistemas de treinamento para cirurgias, por exemplo).

No que concerne à educação à distância (EAD), a RV conquistou seu lugar devido à linguagem VRM L (acrônimo para virtual reality modeling language). A partir desta linguagem, foi possível construir aplicações RV para a Internet. 0 objetivo de desenvolver aplicações baseadas em RV paraa Internet élevar essa tecnologia para o usuário dito "comum". Esta meta pôde ser alcançada também "[...] devido à capacidade de processamento dos computadores pessoais, à difusão das linguagens para RV eo aumento crescente da largura de banda da Internet" 5 .

A VRM L é uma linguagem independente de plataforma que descreve e permite a criação de ambientes virtuais em três dimensões para a Internet, por ondese podenavegar, visualizar objetos por ângulos diferentes e até interagir com eles, mudando ou não suas características. Páginas web precisam ser aptas ao rápido acesso e execução. Por isso, suas aplicações devem ser motivadoras e, ao mesmo tempo, eficazes. Tal necessidade justifica o fato de os sistemas criados em VRM L não proverem altosníveis deimersão. Outro ponto a se observar é a necessidade de os elementos que compõem as aplicações para web terem reduzido número de ângulos, do contrário tornariam a execução da aplicação demasiadamente lenta. Isso justifica a simplicidade das geometrias apresentadas.

Há bem pouco tempo, podia-se considerar que o grande potencial de utilização da RV destinava-se a pequenos grupos alocados nos grandes centros urbanos e instituições de ensino e pesquisa. Entretanto, a integração RV-VRM L democratizou seu acesso, ampliando ainda mais seu potencial e campos de utilização.

Para visualizar e interagir com um cenário em VRM L, é necessária a mediação dos chamados plug-ins para a Internet, programas capazes de decodificar os comandos VRM L. Alguns exemplos disponíveis gratuitamente na Internet são: Cortona, Bitmanagment Contact e 0 ctagePlayer.

Outra possibilidade para a disponibilização de aplicações baseadas em RV na Internet éa tecnologia Shockwave. Para esta tecnologia, as aplicações são desenvolvidas pelo pacote proprietário M acromedia Director. O Director permite a criação de conteúdo multimídia interativo ecomplexo para distribuição em mídia bem como na Internet. A diferença marcanteentrea VRM L ea Shockwave é o fato desta última dispensar o uso de linhas de programação.

\section{A tecnologia de RV na educação}

Considera-se que, para o campo da educação, os produtos informáticos ganharam lugar significativo, principalmente devido à sua característica de impor "o fazer" tanto para educandos quanto para educadores e isto, por si só, já é educativo. No quese refereà RV, uma de suas peculiaridades que interessa à educação é o fato de adequar-se a diferentes formas de aprender, ou seja, a cada estilo cognitivo. Para pessoas com dificuldades no entendimento de equações, teorias e princípios, por exemplo, a RV pode ser usada para "materializar" formas de demonstração, dando-Ihes maior grau de concretude. Para aqueles que são 
visuais e não verbais e preferem gráficos e imagens a explicações e fórmulas, a RV novamente é útil, principalmente em função de seu aspecto altamente visual. Já para pessoas que preferem aprender pela exploração em vez da dedução, esta tecnologia podepermitir a análise detal hada muitas vezes impossível por outros meios, ou seja, para aqueles que aprendem melhor de forma ativa, interagindo com o ambiente, em vez ao invés de um aprendizado passivo, a RV pode criar ambientes altamente interativos, permitindo a manipulação direta dos elementos do ambiente, recebendo resposta imediata às suas ações.

A tendência da educação éfomentar o entendimento da aprendizagem como processo individual e complexo e sustentar-se na visão global do mundo fruto das vivências do indivíduo, inter-relacionada com o desenvolvimento de capacidadesligadas à observação, análise, planejamento, decisão, aplicação e avaliação. Para isso, a RV pode revelar-se como recurso potente, uma vez que propicia a visual ização, interação e resposta em tempo real.

Jáa integração da tecnologia RV à educação à distância(EAD) contribuiu para aumentar a qualidade desses processos educativos, uma vez que a comunidade de aprendizagem, além da comunicação já provida pelos ambientes virtuais educacionais disponíveisnal nternet, ainda podeconsubstanciá-la com o relato de experiências vividas em tempo real. Além disso, a chamada "RV de monitor" contribui para a humanização da EAD na medida em que permitiu ao aluno imprimir um caráter pessoal através não só da seleção dos caminhos pelos quais deseja percorrer e seus elementos de interação, mas determinando formas individuais de conduta no mundo virtual (no caso da utilização de personagens virtuais ou avatares).

As formas humanas de apreensão são multimodais ${ }^{6}$ e, no que concerne aos pressupostos construtivistas da aprendizagem, isso significa colocar o aluno como centro do processo de aprendizagem e, ao mesmo tempo, dar-Iheosinstrumentos necessários para tal (experienciação decisão), mormente no campo das ciências da saúde, no qual a visualização e manipulação de elementos tridimensionais são primordiais para o desenvolvimento de competências técnicas.

Como exemplos da aplicação da RV em propostas educativas (tanto à distância quanto para apoiar o ensino presencial), pode-se citar:

. os ambientes virtuais colaborativos (collaborative virtual environments - CVE) - Second Life (SL - segunda vida). Trata-se de um ambien- tevirtual etridimensional quesimula, em alguns aspectos, a vida real esocial do ser humano. Pode ser entendido como "ambiente paralelo" no qual o indivíduo "prolonga" sua vida real (real life) através da expansão de sua rede de convívio em um ambiente virtual que, embora visualmente simples, provê as "mesmas" formas de atuação e interação do mundo real. No que se refere a ambientes virtuais educativos, as aplicações SL têm sido utilizadas para expandir a interação entre as comunidades de apren dizagem, onde os estudantes se encontram e participam de atividades acadêmicas independente de tempo e espaço;

- as cavernas digitais (CAVE), interessantes para a educação por que fomentam a percepção mútua, a noção de compartilhamento, cooperação e, principalmente, o convívio social dentro de um cunho educativo - pressuposto do socioconstrutivismo e;

. 0 desenvolvimento de aplicações educacionais que integram recursos de RV em dispositivos móveis, como celulares, tablet PC, pocket PC e iPod VR display. Estes dispositivos são considerados instrumentos da chamada aprendizagem móvel (ou mobile learning).

O futuro, acredita-se, decorrente do resultado do processo de maturação das tecnologias interativas éa chamada computação ubíqua. Previsto por M ark Weiser em 1988, este termo carreia a idéia de os computadores tornarem-se onipresentes e invisíveis ${ }^{7}$. Para 0 autor, uma importante transformação, necessária a esta onipresença digital, seria o conceito de tecnologia calma (calm technology), a qual propõe que o sistema deva ser capaz de aproveitar o centro ea periferia da atenção do usuário, chamando, assim, pouca atenção para si.

No campo das ciências da saúde, especificamente, as aplicações datadas do final da década de noventa giravam em torno dos diversos tratamentos (terapêuticos) com recursos tridimensionais e audiovisuais capazes de simular, com segurança, as diversas situações relativas ao processo de tratamento.

De lá para cá, no que se refere à RV de monitor (com ou sem uso de capacete e luva), observa-se aplicações que se voltam para o campo da saúde mental como, por exemplo, as destinadas ao tratamento de fobias: aracnofobia (medo de aranhas), climacofobia (de subir ou descer ou de cair), aeroacrofobia (aversão e medo mórbido a lugares altos e abertos), claustrofobia (aversão e medo mórbido a lugares fechados), além das fobias sociais, tratamento de pacientes com grande sofrimento físico (queimados, por exemplo) etra- 
tamentos odontológicos; estas três últimas, destinadas a desviar a atenção dos pacientes de sensações de dor para situações do mundo virtual ${ }^{8}$.

A área médica, principalmente, seben ficiadeste campo de estudo de interface, com aplicações voltadas para formação do profissional no que concerne ao treinamento de técnicas de diagnóstico e intervenções invasivas. Já se pode encontrar no mercado ferramentas de visualização tridimensional, agora acompanhadas pela sensação de tato (por exemplo, a empresa japonesa NTT Comware - http://www.nttcom.co.jp/english/news/en 07062001.html).

Um sistema baseado na tecnologia RV já bem difundido no campo médico éa telepresença (teleoperação, telerrobótica, tele-existência). Esta tecnologia amplia as capacidades motoras e sensoriais humanas, assim como a capacidade de resolver problemas em um ambiente remoto. $\mathrm{Na}$ telepresença, um robô encontra-se fisicamente separado de seu operador humano, o qual executa as operações que são realizadas pelo robô à distância ao mesmo tempo em que emite uma resposta (feedback) sensorial ao operador humano. Isso faz com que o operador tenha a sensação de estar presente no ambienteremoto. Este sistema é muito utilizado em cirurgias remotas pois, além de possibilitar cirurgias à distância, contribui para que os procedimentos sejam menos invasivos e mais precisos (as dimensões das incisões são programadas previamente).

Pode-se citar, ainda, a realidade aumentada (augmented reality), sistema que possibilita a sobreposição de objetos virtuais gerados por computador em um ambiente real, utilizando, para isso, algum dispositivo tecnológico. Esta tecnologia enriquece e amplia a visão do mundo real, uma vez quelheadiciona informações. Estesistemajá foi utilizado em procedimentos cirúrgicos, nos quais o cirurgião tinha informações adicionais projetadas sobre o campo cirúrgico ${ }^{1}$.

No campo da Saúde Pública, alvo do presente trabalho, foi encontrada na literatura apenas uma aplicação, revelando a lacuna existentenesta área no que concerne ao desenvolvimento de aplicações em RV, acredita-se pelo reduzido interesse comercial da área, no treinamento da inspeção de focos de dengue ${ }^{9}$.

O sistema, denominado Sherlock D engue, visa permitir que, via Internet, qual quer pessoa possa aprender como identificar e combater os focos de dengue em sua residência, bem como em locais como galpões, barracos e outros ambientes alvos do mosquito transmissor da dengue.

\section{O estudo decaso}

No âmbito da saúde pública, geralmente, os dados coletados acerca das populações são a base para a tomada de decisão das políticas de saúde. Estes dados geram ações de intervenção e combate às situações e/ou condições desfavoráveis à vida. Isso se aplica aos levantamentos antropométricos, os quais orientam a tomada de decisão referente à ingestão de nutrientes dos grupos populacionais brasileiros. Obviamente, tais ações envolvem a aplicação de investimentos públicos e, por isso, a meta é criar mecanismos que contribuam para assegurar que os processos deconstrução eimplantação dessas políticas fundamentem-se em dados confiáveis.

Apesar de serem atividades aparentemente simples, medir epesar são procedimentosimportantes, pois revelam informações pertinentes ao estado nutricional dos cidadãos. Estar capacitado ou não para a realização destes procedimentos pode significar precisão ou distorção destas informações, mormente em um país com a extensão geográfica do Brasil, onde, além de profissionais do campo da saúde, ainda atuam líderes comunitários e agentes comunitários de saúde.

O levantamento antropométrico é um dos procedimentos ligados à Vigilância

Alimentar e Nutricional (VAN) do sistema de saúde, sendo esta, seus conceitos, elementos eprocedimentos, alvo de um dos cursos de capacitação profissional ofertados pela educação à distância (EAD) da ENSP/Fiocruz - o curso de aperfeiçoamento em VigilânciaAlimentar eN utricional.

A ideia do presente estudo, portanto, foi desenvolver um ambiente virtual de aprendizagem (AVA) complementar para este curso, apoiado na tecnologia RV, para contribuir com o desenvolvimento de habilidades ligadas aos procedimentos antropométricos, incluindo-sea calibração dos instrumentos, posicionamento dos pacientes, deslocamento de cursores, leitura e registro de resultados.

0 curso destina-se a profissionais, agente locais de saúde, assim como para todo pessoal envolvido no sistema deVAN. Possui uma carga horária total de 180 horas, para as quais o al uno deve dedicar-se aos estudos por um tempo médio de quatro a seis horas semanais. 0 material didático do curso é composto por uma fita VHS, um CDROM, três livros (Guia do aluno: normas e informações sobre o curso, o diagnóstico nutricional, entreoutrostemas) eum ambientevirtual deaprendizagem (AVA) restrito à comunidade de aprendizagem, destinado à comunicação e interação. 
M esmo contando com diferentes mídias, as técnicas antropométricas, as quais requerem 0 desenvolvimento de habilidades físico-motoras, são contempladas pelo material didático do curso apenas através de recursos de visual ização bidimensional. I sso sedeveu à limitação tecnológica da época do lançamento do curso (1999). Entretanto, agora, aliar demanda, processo pedagógico e tecnologia motivou o desenvolvimento deste trabalho.

O protótipo foi aplicado como AVA complementar do curso referido, na busca por provar a hipótese de que a tecnologia de RV poderia contribuir para 0 desenvolvimento de habilidades motoras em processos educativos à distância em saúde pública.

\section{Desenvolvimento do protótipo}

\section{Modelagem 3D}

A elaboração da modelagem tridimensional dos instrumentos utilizados para a real ização dos procedimentos de pesar e medir baseou-se em imagens produzidas no Centro de Saúde Escola Germano Sinval Faria (CSEGSF) da EN SP/Fiocruz, unidadeintegrantedaENSP/Fiocruz, o qual se constitui como centro colaborador em alimentação enutrição da Região Sudeste. N este centro, os procedimentos antropométricos são realizados de forma rotineira nos programas de saúde da família, da mulher, da criança e do idoso, sendo uma das atividades que precedem a consulta médica ambulatorial (tais procedimentos foram usados como referência para a construção dos model os tridimensionais).

As imagens digitais capturadas (fotografadas) foram utilizadas como base para a elaboração da modelagem 3D e suas texturas, de forma a construir model os mais reais possível.

Para a modelagem, foi utilizado o pacotecomputacional 3D Studio M ax (ou simplesmente 3D M ax), um programa (software) profissional para modelamento, animação e renderização de alta qualidade, com luzes, sombras, transparências, etc. Com a renderização, é possível criar imagens fotorealísticas, simulando ambientes, cenários e outros recursos de objetos tridimensionais. É considerado um dos principais softwares proprietários para geração de animação digital tridimensional.

Além das propriedades apresentadas, o 3D $M$ ax foi utilizado no presente estudo pelo fato de exportar arquivos em formato VRM L. Alguns dos modelos elaborados são apresentados na Figura 1.

\section{A interface}

A fim de prover o acesso ao protótipo/aplicação de forma remota, o projeto previu a construção de uma ambiente virtual (HTM L) disponível na Internet, o qual se encontra "hospedado" no provedor da EAD da ENSP/Fiocruz. É na interface que 0 conjunto de ambientes virtuais encontram-se disponíveis para o acesso da comunidade de aprendizagem (estudantes, tutores e orientadores de aprendizagem).

A partir da tela de entrada, 0 aluno pode selecionar um dos sub-ambientes subdivididos em: (a) Para visualizar - animações 3D dos procedimentos antropométricos; (b) Para visualizar e manipular - aqui 0 aluno pode manipular os instrumentos 3D, aproximando-os e girando-os em todas as direções; (c) Para visualizar, manipular e interagir (Figura 2) - área apoiada em $R V$, na qual o aluno realiza os procedimentos e exercícios (preenchimento dos campos com os seguintes dados: resultado da pesagem ou medição, nome e email). 0 sistema trabal ha com cinco diferentes resultados (pesos), apresentandoos al eatoriamente e (d) Contando uma história - (estudo de caso): sub-ambiente destinado à avaliação da aprendizagem do aluno, através de comentários sobre um caso específico. Esta área provê a oportunidade de 0 aluno manifestar 0 conhecimento apreendido através da expressão de sua realidade. Aliado a isso, possibilita o diálogo professor/aluno, uma vez que as respostas são comentadas pelo professor (tutor).

\section{M etodologia deavaliação}

Não se podeavaliar um sistema educacional apenas por critérios técnicos (portabilidade, eficiência, etc.), uma vez que recursos voltados para aprendizagem envolvem fatores multidisciplinares (pedagógicos, culturais, sociais, políticos, mentais, etc.), fazendo de seu processo avaliativo tarefa complexa e delicada, mesmo porque a utilização de tais recursos somente se justifica quando 0 objetivo é a qualidade da aprendizagem ${ }^{10}$.

Osindicadores (critérios) técnicos estão ligados à usabilidade (segurança, eficiência, facilidadedeuso eflexibilidade), aplicabilidade (navegabilidade, comunicação gráfica, legibilidade do conteúdo textual) e funcionalidade (utilidade). Já os pedagógicos referem-se ao perfil do usuá- 
Pesagem: balanças analógicas

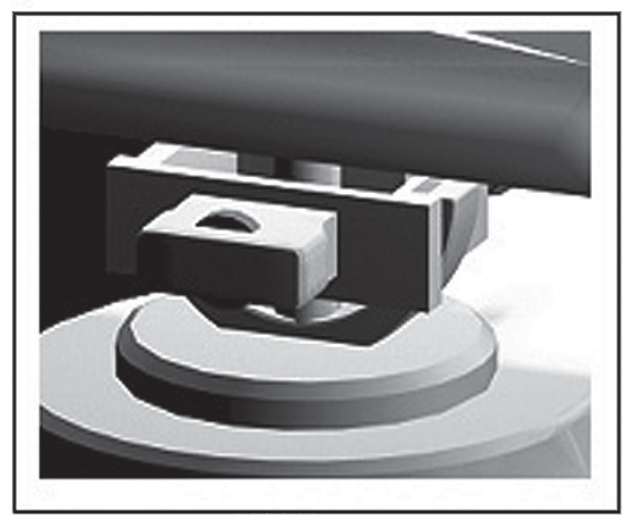

crianças

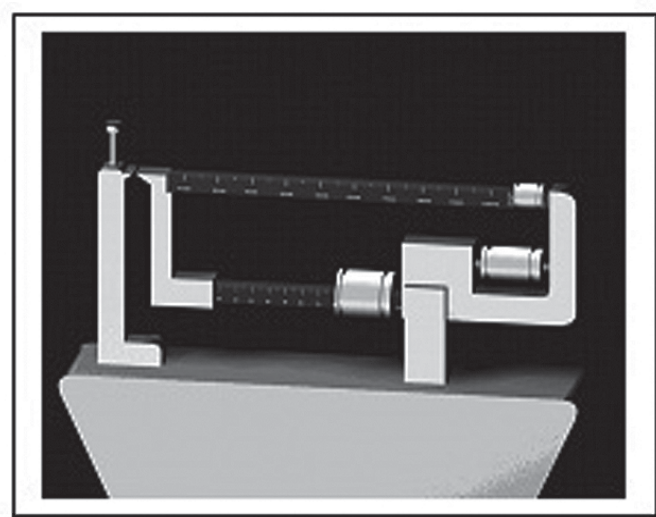

adultos

Medição
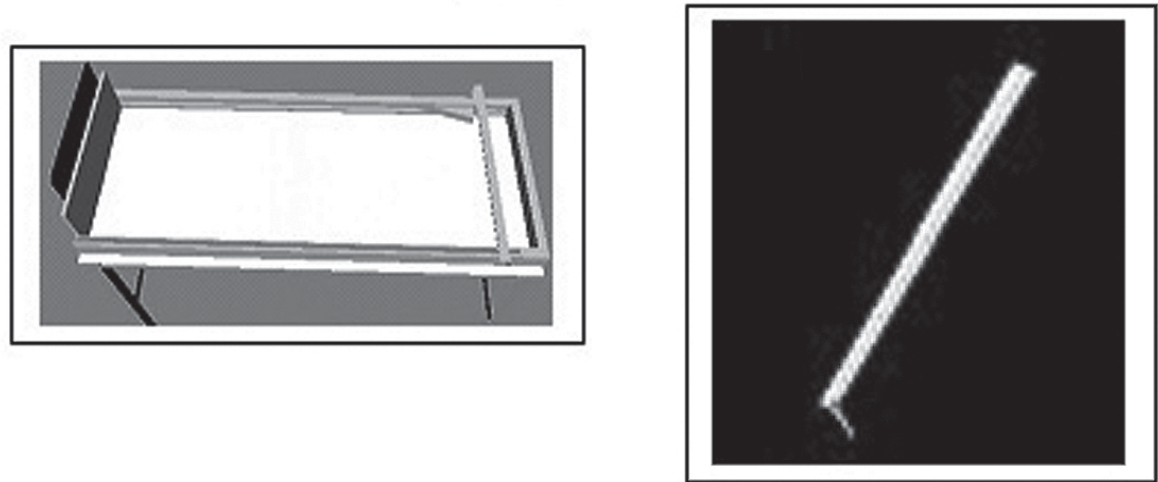

Figura 1. M odelos tridimensionais.

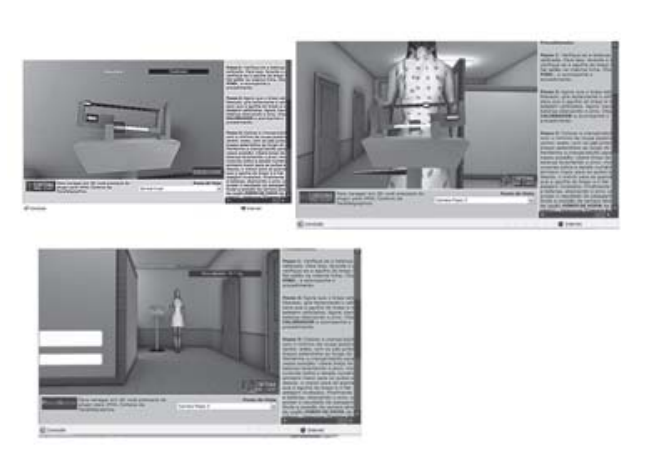

Figura 2. Para visualizar, manipular e interagir: área para realização de exercícios.

rio/estudante, experiência, nível deinteresseeentendimento. Os indicadores pedagógicos são mais qualitativos e, por isso, utilizam métricas subjetivas, ao contrário dos indicadores técnicos mais quantitativos.

Para estruturação dos indicadores técnicos e pedagógicos, a pesquisa utilizou o modelo GQM (goal question metric), um método orientado por objeti vos que se destina a caracterizar e fornecer um melhor entendimento sobre os processos, produtos, ambientes e recursos de forma contínua. Tal característica se adéqua aos princípios construtivistas da aprendizagem, os quais exigem um acompanhamento contínuo e processual. Considera-se que o método possua três níveis de realização ${ }^{11}$ : (1) conceitual - definição do escopo ou objetivo a ser medido (processo, produto, ambiente, recurso, etc.); (2) operacional conjunto de questões que ajudam a caracterizar o objeto e sua relação no contexto de qualidadee (3) quantitativo - definição das métricas ou do conjunto de dados a serem obtidos em relação a cada uma das questões apontadas. 
Desta forma, os elementos do modelo GQM são: (a) objetivo - envolvendo três aspectos: objeto do estudo (produto ou processo); propósito (determinar, caracterizar ou melhorar algum aspecto de qualidade do objeto a ser avaliado); foco de qualidade; (b) questões - informações expressas em linguagem natural; as respostas devem ser concernentes aos objetivos e (c) métricas - expressam em termos quantitativos (passíveis de mensuração) as respostas que se deseja obter.

Por outro lado, adotou-se o modelo teórico denominado apreciação analítica (AA), o qual se baseia na observação, análise ejulgamento como estratégia adequada para aplicação nas fases de planejamento edesenvolvimento e para a seleção de materiais educativos ${ }^{12}$. Por isso, pode ser utilizado tanto na construção da proposta pedagógica, quanto na seleção e validação de softwares e ambientes educacionais.

Este modelo foi aplicado para avaliar um sistema multimídia para processos educativos ligados ao tema sistemas de informações geográfi$\operatorname{cas}^{13}$. Neste estudo, os sujeitos envolvidos no modelo de AA receberam a denominação de profissionais especialistas (PE). 0 objetivo dessa adaptação foi possibilitar a apreciação multidisciplinar do sistema ou sua avaliação segundo diversos "olhares". Para tal, a autora constituiu a equipe de avaliadores distribuídos nos seguintes perfis de PE eáreas: tecnologia educacional, tecnologia de software, do tema alvo do conteúdo do sistema, design, docentes e alunos (profissionais do campo da saúde pública). 0 instrumento deAA utilizado (questionário) continha questões básicas, as quais foram respondidas pelo conjunto de PE, equestões específicas, de acordo com o perfil dos mesmos.

0 presenteestudo, portanto, propôs o modelo de avaliação métrico pedagógico (M AM P), fruto da integração dos métodos GQM e apreciação analítica, utilizando indicadores emétricas técnicas (baseadas na interação homem-computador) e pedagógicas esquematizados na Figura 3.

Assim, a validação do produto (protótipo) foi realizada pelos $P E$, além de amostras de estudantes, profissionais e agentes comunitários de saúde. Estes sujeitos interagiram com o AVA, realizaram as estratégias de avaliação da aprendizagem e, finalmente, responderam ao questionário de validação.

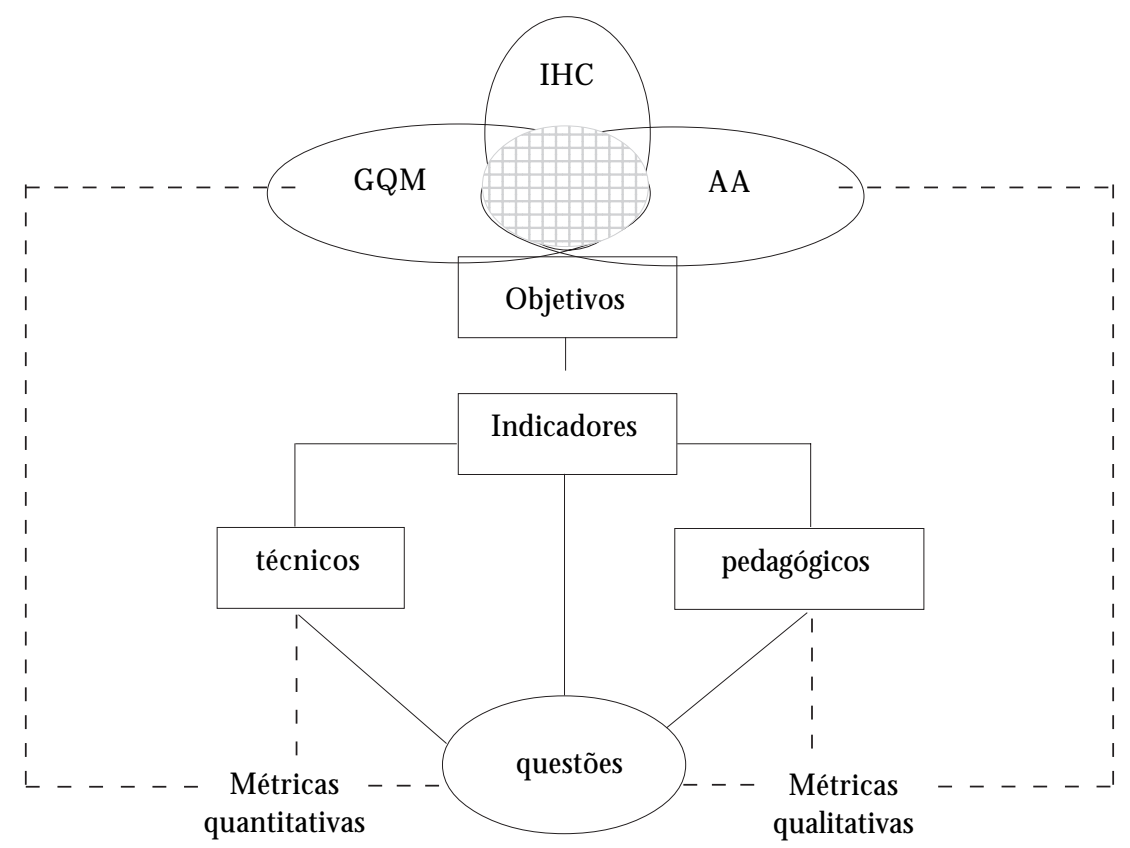

Figura 3. M odelo de avaliação métrico-pedagógico (M AM P). 


\section{Resultados}

No total, 189 voluntários interagi ram com o AVA, sendo distribuídos em dois grupos, os que interagiram presencialmente eos queinteragiram de forma remota.

Pelo fato de a metodologia de avaliação prever a interação com a tecnologia de RV, a participação nas atividades de verificação da aprendizagem (exercício e estudo de caso) e o preenchimento do questionário de $A A$, foram considerados como participantes do processo de avaliação do protótipo apenas aqueles que executaram todas as tarefas previstas. Desta forma, foram descartados 92 voluntários (todos integrantes do grupo de acesso remoto) sendo, portanto, consi derados como reais participantes apenas 97 voluntários. Deste contingente, quinze voluntários participaram do denominado momento de avaliação presencial (encontro organizado pela coordenação do curso a partir das orientações determinadas pela teoria de $A A$, realizado no dia 11/07/2007, na sala multimídia da sede da EAD/ ENSP) e, devido à flexibilidade de acesso da Internet, 82 participaram à distância:

. Momento presencial: realizado por quatro $\mathrm{PE}$, uma aluna ativa do curso, oito profissionais de saúde, dois agentes comunitários de saúde (ACS), um professor/tutor. A pós a interação com o ambiente e preenchimento do instrumento deAA (aproximadamentequarenta minutos), os participantes (exceto especialistas) foram conduzidos ao Centro de Saúde da ENSP/Fiocruz, onde realizaram o procedimento apreendido no AVA, no mundo real. Os ACS, bem como os profissionais, foram selecionados pelo centro colaborador dentre os inscritos que não tinham tido contato prévio com os procedimentos antropométricos ou qualquer atividade de aprendizagem correlata;

. À distância: a AA foi realizada por 82 pessoas através do acesso remoto (endereço eletrônico http://www.extranet.ead.fiocruz.br/elomar), divididas em sete estudantes, cinquenta 50 profissionais de saúde, quinze docentes do ensino presencial e dez docentes do ensino à distância (tutores).

Tanto no momento presencial (80\%) quanto "à distância" (79,26\%) , a mai oria dos participantes utilizava computador em casa e no trabalho, inclusive os ACS (sugerindo uma mudança importante no que concerne à democratização do acesso à informática). Além disso, todos os participantes do momento presencial possuíam endereço eletrônico (email) válido.
Do momento presencial, $86,6 \%$ dos participantes e 90,24\% "à distância" reportaram não haver erros no sistema, sendo considerado, portanto, muito seguro (3,65\% apontaram dois erros de digitação presentes em todo o conteúdo textual). Aliado a isso, 66,6\% dos participantes presenciais e 84,14\% dos "à distância" consideraram claras as orientações, subsídios e objetivos; $53,3 \%$ do momento presencial e 84,14 "à distância" consideraram o padrão gráfico como muito bom; $73,3 \%$ do momento presencial e $97,5 \%$ "à distância" consideraram a linguagem utilizada muito clara. Cem por cento consideraram a navegação e orientação do AVA clara, o que sugere ser o sistema amigável.

Os exercícios propostos foram considerados adequados por $100 \%$ dos participantes. Cem por cento ainda declararam ter sentido prazer ao utilizar o sistema e, no que se refere à tecnologia de RV como recurso pedagógico potencializador da aprendizagem, 93,3\% dos participantes do momento presencial e $100 \%$ dos "à distância" declararam que a mesma colaborou com seu processo deaprendizagem. Apenas um participantepresencial declarou ter sido indiferente (integrante do grupo de PE).

A avaliação da aprendizagem foi realizada por meio da realização dos procedimentos de pesagem (adulto e menores de quatro anos), cujos resultados foram enviados por email para apreciação e comentários do tutor, assim como através da apreciação e resposta do estudo de caso proposto (também enviado para o tutor).

\section{Consideraçõesfinais}

A RV é mais fortemente indicada para o treinamento de atividades e/ou tarefas que exijam 0 desenvolvimento de capacidades técnicas especializadas, configurando-se, portanto, como recurso potente de ensino, mormente para o campo da saúde. $\mathrm{Na}$ pesquisa bibliográfica brasileira, foram encontradas aplicações arrojadas no campo da educação médica (o que já tranquiliza). No campo da saúde pública, entretanto, foi encontrada apenas uma aplicação restrita à visualização. Estefato sugeriu o ineditismo do presente trabalho, o qual traz como principais destaques: (1) a tecnologia de RV foi considerada como um recurso pedagógico adequado para a formação profissional presencial e à distância no campo da educação em saúde pública; (2) aplicações baseadas em RV podem ser utilizadas como instrumento de avaliação formativa, pois propici- 
am um levantamento diagnóstico do perfil dos profissionais (alunos) no que concerne às suas habilidades prévias e posteriores (resposta ime diata - feedback quanto às habilidades e competências desenvolvidas); atuam como objeto de aprendizagem, uma vez que a aplicação pode ser reutilizada em diferentes estratégias pedagógicas; colaboram com o autoestudo pois, respeitando as características individuais e ritmos de aprendizagem, podem ser ( $r$ ) visitadas independentemente de tempo e espaço; podem ser utilizadas em contextos educativos construtivistas, pois os métodos de desenvolvimento das atividades podem ser alvos do diálogo tutor-aluno (o erro podeser o início detudo); são consideradas como material pedagógico motivador para processos educativos à distância, pois promovem a busca intuitiva; colaboram com processos educativos calcados na teoria da apren dizagem significativa, uma vez que são capazes de reproduzir as atividades e situações do mundo real e, finalmente, pelo que foi demonstrado através dos resulta-

\section{Referências}

1. Barilli EC. A plicação de M étodos e Técnicas de Realidade Virtual para Apoiar Processos educativos a Distância que Exijam o Desenvolvimento de Habilidades M otoras: um Ambiente Virtual para a Aprendizagem dos Procedimentos Antropométricos Ligados ao Sistema de Vigilância Alimentar e Nutricional do Sistema de Saúde Brasileiro [tese]. Rio de Janeiro (RJ): Coordenação de Programas de Pós-Graduação em Engenharia, UFRJ; 2007.

2. Axt M, Schuch EM M. Environments of virtual reality and education: what is this reality? Interface (Botucatu) 2001; 5(9):11-30.

3. Cunha GG. M aterial de A poio Didático: Introdução à Realidade Virtual. Rio de Janeiro: Programa de Pósgraduação em Engenharia Civil/; 2001. [M imeo]

4. Souza DFL, Moraes RM, M achado LS. Incorporação de Sistemas Hápticos em Aplicações de RV. In: Anais do I Workshop de Aplicações de Realidade Virtual [CDROM ]; 2005; U berlândia.

5. Garcia FLS, Camargo F, Tissiani G. Metodologias para a Criação de Ambientes Virtuais Tridimensionais. In: Anais do $15^{\circ}$ Simpósio Nacional de Geometria Descritiva e Desenho Técnico. 2004; São Paulo.

6. Treviranus J. Adding Feeling, Sound and Equal Access to Distance Education. Adaptative Technology Resource Centre. [site da Internet] [acessado 2007 abr 20]. Disponível em: http://www.utoronto.ca/ atrc/rd/library/papers/TREVIR_J.html

7. Annibal OL. Computação ubíqua. [site da Internet] [acessado 2008 abr 20]. Disponível em: http://www. gta.ufrj.br/grad/02_2/leandro dos aqui expostos, a RV é uma tecnologia passível de ser utilizada como instrumento pedagógico para colaborar com processos de formação profissional à distância que exijam desenvolvimento de habilidades motoras.

\section{Colaboradores}

ECVC Barilli foi responsável pela realização da pesquisae redação do artigo; NFF Ebecken foi o orientador do trabalho de tese e GG Cunha foi o orientador de tecnologia (construção da interface).

\section{Agradecimentos}

Ao CN Pq (apoio financeiro ao Programa deA poio a Pesquisa em Educação à Distância - PAPED).
8. Costa F, Pietrobon L, Fadela M, Filho R. Utilização da Realidade Virtual em Odontologia. In: Anais do X Congresso Brasileiro de Informática e Saúde; 2007; Campos do Jordão.

9. Schimits QT, Kemczinski A, Hounsell ML. Realidade Virtual no Treinamento da Inspeção de Focos de Dengue. In: Anais do IV Workshop de Informática Aplicada à Saúde - CBComp; 2004; Paraná.

10. Gladcheff AP. Um instrumento de avaliação da qualidade para software educacional de matemática [dissertação]. São Paulo (SP): Universidade de São PauIo; 2001.

11. De Souza KD, De Oliveira KM, Anquetil N. Uso do GQM para avaliar implantação de processo de manutenção de software [dissertação]: Brasília (DF): UCBTIC/UCB; 2003.

12. Struchiner M. O Painel de Especialistas no Processo de Apreciação Analítica de Sistemas Hipermídia para o Ensino de Graduação. In: Anais do IV Congresso RIBIE; 1998; Brasília.

13. Barilli EC. Hipersig: sistema hipermídia sobre sistemas de informação geográficas [dissertação]. Rio de Janeiro (RJ): Coordenação de Programas de PósGraduação em Engenharia, UFRJ; 1994.

Artigo apresentado em 20/01/2008

Aprovado em 29/10/2008

Versão final apresentada em 26/11/2008 